\title{
Da harmonização do conflito de interesses ao papel externo do conselho de administração: uma conotação contributiva ao desempenho
}

\author{
Sílvio Parodi Oliveira Camilo, Rosilene Marcon e \\ Rodrigo Bandeira-de-Mello
}

\begin{abstract}
RESUMO
Este artigo visa explorar as atividades externas do board of diretors (Conselho de Administração), demonstrando as diferentes atribuições de seus membros, de modo comparável, à luz das teorias da firma, da stewardship e, especialmente, da dependência de recursos. Por intermédio de uma revisão teórica, o artigo pretende contribuir com os estudos sobre esse tema apresentando a integração de um dos mecanismos internos da governança representado aqui pelo Conselho de Administração, destacando o papel relacional firma-ambiente ancorado na teoria da dependência de recursos. Dessa forma, o artigo está estruturado apresentando a teoria da agência com ênfase nas atividades de monitoramento do board, a teoria stewardship e a teoria da dependência de recursos destacando a importância dos membros do conselho na contribuição com o desempenho da firma. Finaliza, destacando o papel influente do Conselho de Administração, como um importante mecanismo interno de governança das corporações.
\end{abstract}

Palavras-Chave: Conselho de Administração. 0 papel externo do Conselho de Administração. Relação firma-ambiente

\begin{abstract}
This article aims to investigate and discuss the theories associated with the board of directors to corporate governance. From these discussions the

paper demonstrates the different views which theories attribute to the board of directors, establishing a theoretical review, the main construct used as a resource dependency theory to explain the related activities of firms, through the board members. Thus the article discusses the role of the board in the agency's perspective, with emphasis on monitoring activities of the board, the stewardship theory with more confident responsibilities manager, and resource dependency theory stressing the importance of board members in contributing to firm performance. We conclude that the social relations established by external advisors contribute positively in the flow of information from the environment to the firm, hence the contribution made by these members to the activities performed by managers (executives), which provides performance benefits.
\end{abstract}

Keywords:Board of directors, the external role of the board of directors, firm-environment relationship. 


\section{INTRODUÇÃO}

A literatura aponta que a teoria da governança das corporações teve seu impulso marcado pelas discussões sobre o conflito de interesses entre o principalagente e principal-principal, originadas pela teoria da agência. Muitas outras formulações teóricas se associam aos pressupostos da governança corporativa, dentre as quais as teorias da firma (COASE, 1937; ALCHIAN; DEMSETZ, 1972), dos stakeholders (JONES, 1995; DONALDSON; PRESTON, 1995; FLAK; ROSE, 2005), do poder (MINTZBERG, 1984; TOWNLEY, 1993), do stewardship (DONALDSON; DAVIS, 1991; DAVIS; SCHOORMAN; DONALDSON, 1997), da dependência de recursos (DOOLEY, 1969; PFEFFER, 1972; ZAHRA; PEARCE II, 1989; BOYD, 1990; PEARCE II; ZAHRA, 1992; DAILY; DALTON, 1994a, 1994b); e da dependência de recursos associada ao Conselho de Administração (KOENIG; GOGEL; SONQUIST, 1979; BOYD, 1990; HILLMAN; CANNELLA JR; PAETZOLD, 2000; HILLMAN, 2005).

Nessa linha relacional, a literatura estabelece que as firmas planejam e deliberam, com o objetivo de realizar suas estratégias, de várias maneiras, os laços com o ambiente. Tem sido investigada a realização dessa interação firma-ambiente por meio de acionistas, Chief Executive Office (CEO) e membros do Conselho de Administração. Desta forma, este artigo visa explorar as atividades externas do board of diretors (Conselho de Administração), demonstrando as diferentes atribuições de seus membros, de modo comparável, à luz das teorias da firma, da stewardship e, especialmente, da dependência de recursos.
O board, como mecanismo interno de governança das corporações, tem recebido atribuições direcionadas a um papel influente na relação firma-ambiente. Essas ligações externas têm sido explicadas sob a conotação da teoria da dependência de recursos, justamente por se basear num ambiente de recursos escassos. Dessa forma, as firmas estabelecem seus vínculos com o ambiente externo com o objetivo de reduzir as incertezas e a interdependência das organizações, controlando o ambiente (PEFFER, 1972; ALDRICH; PFEFFER, 1976; DAILY; DALTON, 1994a, 1994b). É isso justamente que a teoria da dependência de recursos (TDR) se ocupa, ou seja, tem por base ações das firmas em face das contingências externas. Vê os vínculos externos como uma maneira de assegurar benefícios que podem ser traduzidos em informação, influência, proteção, recursos financeiros e rendas do ambiente externo, como do governo, por exemplo. O Conselho de Administração tem recebido um papel importante para a formação desse elo (AGRAWAL; KNOEBER, 2001).

A partir dessas discussões, neste trabalho, se demonstra as diferentes visões que as teorias atribuem ao Conselho de Administração. Por intermédio de uma revisão teórica, o artigo pretende contribuir com os estudos sobre esse tema apresentando a integração de um dos mecanismos internos da governança: o Conselho de Administração, destacando o papel relacional firma-ambiente ancorado na teoria da dependência de recursos. Dessa forma, o artigo está estruturado apresentando a teoria da agência com ênfase nas atividades de monitoramento do board; a teoria stewardship com atribuições 
mais confiantes ao gestor; e a teoria da dependência de recursos destacando a importância dos membros do conselho na contribuição com o desempenho da firma. Ao final desta seção, antes das conclusões, se destaca o papel influente do Conselho de Administração, como um importante mecanismo interno de governança das corporações.

\section{FUNDAMENTAÇÃO TEÓRICA}

Neste capítulo será tratado sobre a Teoria da Agência, a Teoria Stewardhip, Teoria da Dependência de Recursos e o Conselho de Administração como mecanismo interno.

\subsection{Teoria da Agência}

Por decorrência da segregação entre a propriedade e o controle, na teoria da agência, se destacam dois problemas discutidos pela literatura: (a) conflitos de agência e (b) custos de agência. Desses problemas, vários aspectos são tratados por investigadores, dentre os quais: (a) fragmentação das decisões, complexidade contratual, divergência de interesses, destinação dos recursos; e (b) custos com monitoramento, compartilhamento de resultados, formalidade contratual, agente ideal. Esses pontos são apresentados a seguir.

A teoria da governança corporativa se desenvolveu a partir das considerações do trabalho de Jensen e Meckling (1976), fundamentalmente sobre questões que envolvem as relações entre o principal e o agente. A segregação da propriedade/ gestão envolveu fragmentação nos tipos de decisões, ou seja, as preocupações do principal passaram a ser outras; o modelo do processo de decisão anterior foi ampliado e diluído. Por outro lado, a difusão do processo decisório também gerou benefícios, dentre os quais, a atuação do principal em estágios mais fundamentais para solucionar determinados problemas de agência (FAMA; JENSEN, 1983).

De fato, as divergências decorrentes dessa relação são inevitáveis, apesar dos termos ajustados por contratos formais e informais. Klein (1983) asseverou que, em razão da complexidade, os contratos não podem prever todas as condições impostas por forças contingenciais. Além disso, uma instrumentalização mais abrangente inviabilizaria o objeto contratual, tornando-o altamente custoso. Por esse motivo, o autor concluiu que os "contratos são incompletos". Os objetivos e metas esperados pelo principal muitas vezes não são cumpridos pelo agente e há dificuldades em acompanhar o que o agente está de fato fazendo; isso impõe aos acionistas e à organização certo grau de risco (EISENHARDT, 1989). A relação insegura e conflituosa envolve negociação e barganha, conduzindo para resultados e especificidades formais orientados por contratos.

Como acréscimo ao postulado de Klein (1983), Jensen e Meckling (1994, p. 28), baseados nos pressupostos dos conflitos de agência em suas múltiplas possibilidades, entenderam que nessa relação "não existe agente perfeito". 0 agente perfeito abre mão do seu bem-estar para satisfazer os interesses do capital; em tese, estaria desalinhado dos seus próprios interesses. Essa assertiva se fundamentou no exame da natureza do homem. Os autores concluíram 
que, para compreender como a organização funciona, é necessário entender a mente humana, os modelos mentais associados a comportamentos distintivos.

Questões em aberto no relacionamento de agência foram também destacadas por Hart (1995), sendo pertinentes aos contratos (incompletos) e a problemas de agência. Como forma de atenuar conflitos, ele propôs o fortalecimento das regras estatutárias. A estrutura de investigação proposta por Rediker e Seth (1995) no relacionamento de agência sugere que os interesses não sejam naturalmente congruentes entre os agentes e os acionistas. Ainda que a abordagem oferecida por Adrian Cadbury (CADBURY, 2000) sirva de referência a um contexto geral, as companhias estabelecem certas condições, conforme suas especificidades.

As divergências entre o proprietário e o agente e entre o principal majoritário e o principal minoritário promovem certos mecanismos de defesa, não necessariamente protetores dos interesses da firma social, visto que os interesses não se mostram simétricos. Agrawal e Knoeber (1996), em uma abordagem empírica, examinaram a performance da firma e os meios para controlar os problemas de agência entre os gestores e acionistas. Os achados apontaram para significativa correlação entre performance e os proprietários como gestores internos e entre representantes externos no conselho em firmas com dívidas financeiras. Além disso, identificaram que, quanto maior o número de conselheiros externos, maior a alavancagem das empresas.

Com base em Jensen e Meckling (1976), Fama (1980), Fama e Jensen (1983), Jensen (1986) e Davis e Thompson (1994), pode-se inferir que a literatura identifica predominância da falta de convergência entre os interesses do principal e os do agente e vice-versa. Todavia, o desafio da organização é produzir mecanismos que alinhem tais interesses, em benefício do conjunto, tornando a relação mais harmoniosa. Ao maximizar o valor da firma, os gestores estarão maximizando os investimentos a ela confiados pelos acionistas, minimizando, por sua vez, os custos de agência.

Preocupados com os efeitos garantidores desse contrato, os investigadores aprofundaram os estudos sobre essa formulação. 0 primeiro trabalho de repercussão foi o de Jensen e Meckling (1976), que discutiram questões não resolvidas que envolviam as relações entre o principal e o agente. Com base nas definições da firma formuladas por Coase (1937), Alchian e Demsetz (1972) apresentaram análises dos custos de agência, considerando o capital próprio e o capital de terceiros. Pontuaram a divergência de interesses por parte do principal quando na condição de administrador da firma, em situações em que detém os direitos integrais do lucro residual versus quando vende uma fração dos direitos de propriedade e continua a gerir a firma. Os autores observaram comportamento distintivo entre as duas situações. 0 status de tomador de decisão, no processo de maximização da utilidade, envolve aspectos financeiros e não financeiros nas decisões desse gestorproprietário. 0 compartilhamento dos lucros gerados enseja desejo de compensação por meio da apropriação de recursos da corporação, materializados em benefícios ou em determinadas vantagens. 
Contribuições para minimizar os custos de agência podem ser dadas pelas formas de regulação, normas legais e criatividade na elaboração dos contratos (JENSEN; MECKLING, 1976). Todavia, ainda que modelado por aparato instrumental, o vínculo entre o principal e o agente não evitou o conflito de interesses entre os acionistas (majoritários e minoritários) e esses com o agente na nova realidade das corporações.

Fama e Jensen (1983, p. 6) destacaram que

os problemas de agência se originam porque os contratos escritos, ainda que formalizados, não asseguram a minimização dos custos. Consideraram como custos de agência aqueles relacionados à estruturação, monitoramento e vínculos através de um conjunto de contratos com o agente em conflito de interesses.

Além desses, salientaram os custos inobserváveis constituídos em perdas por não atendimento aos resultados esperados. Segundo Eisenhardt (1989), as pesquisas que abordam a redução dos conflitos entre as partes têm se dedicado a formular o contrato ideal e avaliar o equilíbrio entre comportamento adequado e resultado, buscando formas de minimização de riscos aos acionistas.

Visando novas formas de maximizar o valor da firma e reduzir os custos de agência, outras perspectivas teóricas foram derivadas da teoria de agência, dentre as quais, a teoria stewardship.

\subsection{Teoria Stewardship}

Concepção alternativa à corrente predominante da Teoria da Agência (TA), dando novo significado a essa relação principal-agente, foi discutida no trabalho de Donaldson e Davis (1991), que se apoiou na teoria stewardship (TS) - modelo baseado na gestão da motivação e do comportamento, que tem por escopo o embasamento psicológico e sociológico na escolha do agente. Em contraste com a teoria da agência, Davis, Schoorman e Donaldson (1997) ofereceram nova perspectiva com vistas a minimizar potenciais problemas de oportunismo e, por conseguinte, atenuar o conflito de interesses entre o principal e o agente. Salientaram que a TA, com raízes do campo econômico e financeiro, preocupase fundamentalmente com o binômio monitoramento-incentivo; entretanto, as relações entre o principal e o agente são mais complexas.

Sob esse enfoque, a conduta do agente é entendida como não oportunística; seu objetivo, portanto, não prioriza aspectos financeiros pessoais. Por esse comportamento, sua principal preocupação é agir com diligência em prol dos interesses da firma. E o faz, mostrando-se um guardião dos ativos corporativos. Nessa perspectiva, o fato de a firma ter segregação interna entre a gestão e o conselho, com funções e atividades distintas, conforme sugere a TA, não resulta em maximização de retornos aos acionistas. 0 foco fundamental da TS é abrandar os conflitos com base nas características prescritivas do steward, pautadas na necessidade de crescimento, realização, autorrealização e comprometimento com os propósitos da firma, ou seja, a TS reconhece motivações não essencialmente financeiras no agente.

Percebe-se que esse alinhamento aponta para fortes características de vínculo aos 
interesses da firma e ao conselho, a quem o steward, alinhado, deve subordinação. Nessa visão da TS há uma forma de preservar a cultura organizacional e disseminá-la aos demais subordinados, contribuindo para o equilíbrio das relações (DAVIS; SCHOORMAN; DONALDSON, 1997).

A transferência de atividades de controle ao steward proporciona maior profundidade de conhecimento, acesso amplo a conhecimentos e informações sobre a firma, melhor garantindo a maximização de retorno aos acionistas (MUTH; DONALDSON, 1998). Decorrente dessa confiança e cooperação há certa centralidade do gestor. Em consequência disso, quanto menos intensiva é a participação do conselho no processo de tomada de decisão, maior será sua dependência e a assimetria informacional em relação aos processos decisórios. Por outro lado, nessa consideração, um alinhamento entre os acionistas, o Conselho de Administração e os executivos pode estabelecer novas atividades aos membros do board, como, por exemplo, exercerem um papel proativo no aspecto relacional ao ambiente, e é o que a teoria da dependência de recursos promove.

\subsection{Teoria da Dependência de Recursos}

Relacionar a firma ao ambiente é o propósito do construto teórico da dependência de recursos. A redução da incerteza ambiental pode ser administrada pela empresa, empregando determinadas estratégias (PFEFFER, 1972). Sob essa ótica, a firma é entendida como um organismo ativo, capaz de responder às influências do ambiente externo com adoção de estratégias voluntaristas (PFEFFER, 1972; ALDRICH;
PFEFFER, 1976).

Essa perspectiva pressupõe que as organizações são dependentes do ambiente e suas estratégias devem empreender ações que reduzem a interdependência. Por não serem autossuficientes, o ambiente deve ser considerado como fornecedor de suporte. Essa relação entre a firma-ambiente é um processo de troca. Se as organizações não podem promover, por si próprias, os recursos necessários requeridos, então devem supri-los interagindo com o ambiente (ALDRICH; PFEFFER, 1976). Nesse sentido, há disputa natural do mercado por recursos disponíveis; todavia, estratégias que visem à obtenção de recursos mais qualificados são decisões que a firma deve formular. A organização captura os recursos de que necessita e o ambiente, por meio de grupos ou organizações externas, pode exigir, em troca, certas ações da organização. É esse fato de dependência da organização no ambiente que torna a restrição externa e o controle do comportamento organizacional possível e quase inevitável (PFEFFER; SALANCIK, 2003).

Considerando essa relação firmaambiente, estratégias mais bem concebidas podem capturar recursos e serviços mais qualificados que contribuam para melhores performances. Mesmo assim, estratégias bem concebidas a partir das oportunidades ofertadas pelo ambiente externo não garantem melhores performances. Sobre essa questão, Pearce II (1983) ponderou que a literatura que se ocupa da relação firma-ambiente sugere orientação do planejamento estratégico tanto por uma abordagem interna, baseada na eficiência, quanto externa, para responder aos fatores da competitividade. 
A interação firma-ambiente é importante para a concepção de estratégias que capturem recursos vitais à obtenção de melhores desempenhos. Mas, quais os elos da firma com o ambiente? A literatura tem discutido as formas de relacionamento por meio dos acionistas, CEOs e membros do Conselho de Administração (AGRAWAL; KNOEBER, 2001; LEUZ; OBERHOLZERGEE, 2006; BERTRAND et al., 2006; FAN; WONG; ZHANG, 2007; BOUBAKRI et al., 2008; LI et al., 2008; GOLDMAN; ROCHOLL; SO, 2009). Todavia, sob a ótica da teoria da dependência de recursos, têm recebido atenção, abordagens das ligações e composição do Conselho de Administração baseadas num ambiente de recursos escassos (DOOLEY, 1969; PFEFFER, 1972; BOYD, 1990; PEARCE II; ZAHRA, 1992; DAILY; DALTON, 1994a, 1994b; HILLMAN; CANNELLA Jr.; PAETZOLD, 2000).

Salienta-se que certas atribuições externas da firma são atividades estratégicas exercidas pelo Conselho de Administração. Essas ligações podem ser estabelecidas sob várias formas, dentre as quais, as interligações entre os membros dos conselhos. Por exemplo, Dooley (1969) foi pioneiro ao investigar as participações simultâneas dos conselheiros (interlocking) entre companhias no mercado americano. A aproximação do Conselho de Administração ao ambiente promove oportunidades que contribuem para moldar os objetivos da firma (PFEFFER, 1972), influenciando e promovendo novas concepções. É importante na tomada de decisão estratégica das firmas fazer uso balanceado dos fatores internos e externos, que são determinantes nas escolhas das estratégias. Pfeffer (1972), ao investigar atividades de firmas não- financeiras, destacou práticas externas, tais como: organização de serviços e programas necessários a comunidade, relacionamento com grupos e programas sociais comunitários, relacionamento com agências do governo e com instituições financeiras e investimento de capital.

A mesma investigação revelou que organizações utilizam os seus conselhos de administração como veículos para cooptar ou parcialmente absorver importantes instituições externas com as quais elas mantêm relações de interdependência. A estratégia de cooptação envolve a troca, em algum grau de controle e privacidade, das informações para o prosseguimento de determinados compromissos com o ambiente externo. Pfeffer (1972) destacou que o percentual de diretores internos ou externos pode ser um importante indicador do grau de orientação da organização - se está orientada internamente ou externamente; o tamanho e composição do board são relacionados à intenção de cooptação em determinados setores; as características do board de determinadas firmas e setores estão mais bem relacionadas com a necessidade de lidar com o ambiente externo; a composição e características do board são moldadas pelo ambiente externo, pois objetivam garantir êxito nas operações e fornecimento de recursos para o futuro.

Sobre essa relação, Pfeffer e Salancik (2003, p. 214) lançaram a seguinte indagação: "Por que algumas organizações dão mais atenção para o ambiente político e outras não?". Na visão dos autores, a provável resposta é que o ambiente político é alta fonte de interdependência para algumas organizações. Então, se os interesses 
e estratégias de ligações das firmas ao ambiente são distintos, logo, conclui-se que os papéis exercidos pela firma, necessários à otimização dessa harmonização firmaambiente, tornam-se idiossincráticos e o Conselho de Administração, como elo, tem importante função.

Boyd (1990), ao estudar o papel do board na gestão estratégica, enfatizou que a dependência de recursos tem duas implicações importantes. A primeira é pertinente à influência das pressões do ambiente na composição do conselho. A segunda diz respeito às diferenças na composição que deveriam afetar a performance da firma. A base de dados compreendeu 147 firmas de nove grupos industriais, no período de 1979 a 1984 . 0 autor utilizou o número de interlocks e o tamanho do board como variáveis para medir a ligação da corporação ao ambiente. Outro aspecto importante verificado por Boyd (1990) é que uma das características proeminentes das empresas de alta performance, aquelas que são mais densamente conectadas ao ambiente, é o uso de um quadro mais reduzido de conselheiros. Assim, ao invés de simplesmente concentrar no tamanho do board ou interlocks, a ênfase está nos ricosrecursos que os indivíduos possuem. Firmas interessadas em fornecer amplo crescimento e retorno para os acionistas evitam boards burocráticos dominados por insiders. Em vez disso, atenção especial deve ser dada à seleção de membros-outsiders com ricosrecursos que possam fornecer inestimáveis vínculos com o ambiente.

Ao analisar o ambiente das corporações, estratégias, desempenho passado e a composição de seus conselhos de administração, Pearce II e Zahra (1992) levaram em consideração o tamanho do conselho e a representatividade externa na sua composição. Com base em 119 firmas da Fortune 500, no período 1983 a 1989, apontaram que quanto maior a incerteza de uma firma em relação ao ambiente, mais vulnerável ela estará ao sucesso ou ao fracasso. Esse estudo mostrou que a maior incerteza do ambiente é relativa ao crescimento e à diversificação da firma. Organizações mais dependentes de financiamentos e com baixo desempenho passado foram mais bem associadas ao tamanho do conselho e à participação de conselheiros externos.

Pearce II e Zahra (1992) encontraram suporte para a hipótese de que a composição do conselho - o tamanho e o tipo de conselheiro - foi determinada pelo conjunto de forças do ambiente, pela estratégia corporativa e pelo desempenho passado. Cabe enfatizar que a ampliação do board e a alta representação de membros externos são associadas à cooptação do ambiente e à redução da incerteza na concepção, no desenvolvimento e na execução da estratégia. No aspecto de poder decisório, a ampliação do board pode diluir a centralidade do domínio do CEO.

A perspectiva da dependência de recursos advoga que a representatividade da firma por conselheiros externos pode ser vista como uma estratégia para o gerenciamento ambiental da organização (DAILY; DALTON, 1994a, 1994b). Estudos desenvolvidos por esses autores tiveram por base firmas falidas e em processo de crise financeira aguda. Concluiu-se que o gerenciamento da interdependência com o ambiente externo é importante para 
firmas que enfrentam crises financeiras. Conselheiros externos fornecem certos benefícios, como acesso a recursos e informações, promovendo o fluxo de informações interfirmas. Firmas falidas confiaram mais intensivamente na estrutura de liderança monale (acúmulo de funções), ou seja, atuação simultânea como agente e conselheiro (CEO/board chairperson), com poucos membros independentes no conselho em relação às firmas sobreviventes.

Os trabalhos de Daily e Dalton (1994a) e de Hillman, Cannella Jr e Paetzold (2000) sugerem que pesquisas sobre a adaptação do conselho, em resposta às mudanças ambientais, têm focado nas teorias da agência e da dependência de recursos. Hillman, Cannela Jr. e Paetzold (2000) avaliaram 202 companhias aéreas americanas, no período de 1968 a 1988, identificando 557 conselheiros. Examinaram o papel dos membros do conselho, sob a perspectiva teórica da dependência de recursos, como forma distinta ao papel da agência. Enfatizaram que a simples categorização dos conselheiros em internos e externos, não expressa adequadamente suas atividades e influências. Ao proporem nova forma de classificação dos membros do board, dessa base, identificaram a seguinte composição: $24 \%$ insiders, $47 \%$ business experts, $17 \%$ support specialists e $10 \%$ community influentials.

Hillman, Cannela Jr. e Paetzold (2000) concluíram que a função do conselho como um link para o ambiente externo é importante e que as firmas respondem a mudanças significativas no seu ambiente externo, alterando a composição do conselho, o que demonstra a importância do ambiente na estrutura e composição do board.

Em adição, destacaram que empresas não regulamentadas têm menor proporção de conselheiros com influência na comunidade empresarial, visto que a mudança do status das firmas, de não regulamentada para regulamentada, em resposta às exigências ambientais, tende a alterar a composição do board.

Outro aspecto importante desse trabalho foi a identificação, durante a regulamentação, da composição e característica dos membros do conselho. De fato, houve mudanças de conselheiros classificados como insiders e support specialists para o ingresso de business experts e community influentials. Ao final, os autores constataram que essas ligações se assemelham ao board interlocking, que serve para reduzir a incerteza, a interdependência e os custos de transação. Sugeriram, para futuros estudos, associação entre a composição do conselho e a performance das firmas.

Como advertiram Pfeffer (1972), Bazerman e Schoorman (1983), a interdependência da organização com o ambiente externo pode comprometer sua autonomia e aumentar a incerteza do futuro. Num cosmo de intensas e rápidas transformações, de cenários tão mutantes, as atividades prestadas por conselheiros em outras organizações podem contribuir para minimizar a dependência externa. A integração de conselheiros é uma forma de maximizar relações no âmbito empresarial e social.

A literatura aponta que essas ligações interorganizacionais têm promovido certos benefícios às organizações, contribuindo na redução das incertezas 
ambientais (SCHOORMAN; BAZERMAN; ATKIN, 1981; BAZERMAN; SCHOORMAN, 1983). As redes de relacionamento podem gerar muitas vantagens às firmas. 0 relacionamento intercompany pode gerar coordenação horizontal, relacionando duas ou mais firmas ao sistema informacional; coordenação vertical, referente aos recursos internos ou externos; expertise amparada nas habilidades e no conhecimento dos conselheiros externos; e reputação conquistada por uma imagem positiva no mercado (SCHOORMAN; BAZERMAN; ATKIN, 1981).

Implicações dessa modalidade de conexão organizacional ao ambiente, facilitada por laços sociais mediados pelo conselho, também são apontadas por outros pesquisadores, como Johnson, Daily e Ellstrand (1996), Westphal (1999), Lynall, Golden e Hillman (2003). Esses autores encontraram oportunidades geradas por essas relações em termos de performance e revelaram a importância de tais laços para empresas de grande porte, que têm necessidade de financiamento externo para o equacionamento de dívidas ou para o funcionamento e crescimento dos negócios, e também para aquelas que atuam em indústria com regulação. Agências reguladoras têm papel de intervir no domínio econômico, fiscalizando préstimos públicos. Nesse aspecto, Nunes et al. (2007), ao discorrerem sobre o regime regulatório no Brasil, ressaltaram que agências reguladoras assumem as funções de "atrair, complementar ou contrariar certos interesses privados e públicos". Acrescentaram que o ambiente submetido à regulação tende a influenciar a agência de normas protetoras da competição, seja pela criação de barreiras que visem reduzir custos de transação, seja por medidas que tenham por meta a manutenção de determinada posição competitiva. Enfim, as firmas buscam se proteger de demandas de interesse público e de novos entrantes. Os argumentos até aqui reunidos colocam em relevo o papel relacional da firma ao ambiente.

A Figura 1 sintetiza os pressupostos que relacionam o Conselho de Administração à performance e apontam para as perspectivas da agência, do stewardship e da dependência de recursos.

Observa-se que na TA o conselho está mais bem associado ao monitoramento do agente e, com isso, se almeja que a firma possa obter melhor desempenho. $\mathrm{Na}$ TS o conselho deposita fidúcia ao agente em razão do seu envolvimento e comprometimento com a organização. Na TDR certas atividades do conselho estão voltadas para o relacionamento com $o$ ambiente, contribuindo para garantir o fluxo

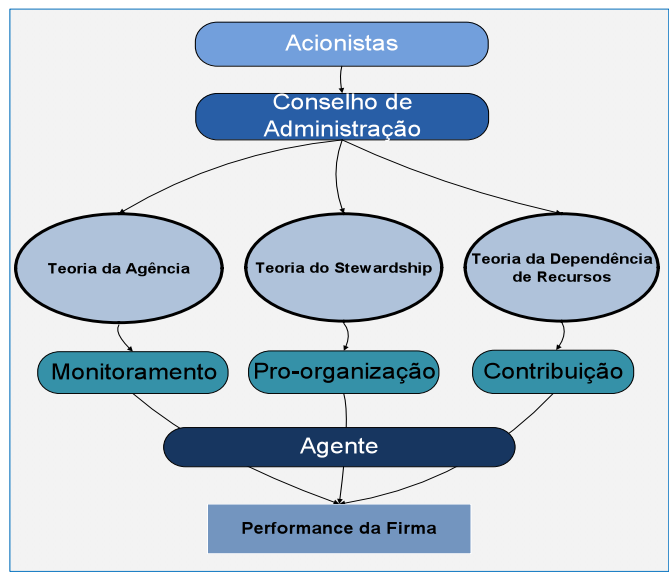

Figura 1 - Perspectivas teóricas do Conselho de Administração Fonte: Elaborada pelo autor 
de recursos à firma, fornecendo suporte ao agente e, consequentemente, obtendo melhoria da performance.

A governança corporativa tem como núcleo o Conselho de Administração. Constituída por um conjunto de mecanismos internos e externos, de âmbito institucional e de mercado, ele orienta os tomadores de decisões sobre a forma como a firma deve ser administrada para atingir a maximização do seu valor e, consequentemente, dos benefícios aos proprietários (DENIS; McCONNEL, 2003).

\subsection{Conselho de Administração como mecanismo interno}

O Conselho de Administração é um mecanismo interno que tem sido objeto de análises e formulações de pesquisadores como Pfeffer (1972), Fama (1980), Fama e Jensen (1983), Zahra e Pearce II (1989), Boyd (1990), Daily e Dalton (1994a, 1994b), Rediker e Seth (1995), Hart (1995), Hillman, Cannella Jr. e Paetzold (2000) e Denis e McConnell (2003).

0 trabalho seminal de Zahra e Pearce II (1989), ao investigar as influências do Conselho de Administração na performance financeira da corporação, abordou quatro perspectivas teóricas: a legalista, a classe hegemônica, a teoria da agência e a dependência de recursos. Estabeleceu as seguintes dimensões comparativas: 0 papel do conselho, a definição operacional do papel do conselho, as origens teóricas, as variáveis de interesse, critérios de avaliação da performance e suporte empírico. Na perspectiva legalista, o papel do conselho tem ênfase na representação e proteção dos interesses dos acionistas, sem interferência nas operações da firma. Na classe hegemônica há forte vinculação com a perpetuação do poder e controle do status capitalista, com influência social e econômica nas instituições.

O Conselho de Administração, ao cumprir a missão de equilibrar os interesses dos gestores e dos acionistas (AGRAWAL; KNOEBER, 1996), assume um papel que exige destacável competência. Dentre as funções do Conselho de Administração, é do interesse deste estudo investigar as atividades externas que contribuem na performance das firmas. Suas relações com o ambiente externo, disputando recursos do interesse da firma, foram consideradas fundamentais, dada a escassez de recursos e os competidores pertencentes à arena (PFEFFER, 1972). Contribuir para minimizar as incertezas é uma atividade complementar que pode ser exercida em benefício da empresa (BAZERMAN; SCHOORMAN, 1983). Nesse sentido, Boyd (1990), ao relacionar o conselho à incerteza ambiental, quanto ao tamanho, sugeriu que ele deve ser bastante amplo para fornecer informações e recursos necessários à firma e deve permanecer bastante pequeno para agir eficientemente. Em suma, o efeito esperado dessa assertiva é que o Conselho de Administração da firma seja, ao mesmo tempo, mais compacto e constituído de conselheiros com experiência relacional com o ambiente externo.

A exploração desses canais de conexão possibilita a captação de negócios e a geração de resultados à firma, garantindo o fluxo de recursos essenciais à continuidade e à geração de valor. Flak e Rose (2005), com base em Donaldson e Preston (1995), adaptaram a teoria dos stakeholders à governança eletrônica, com a finalidade de 
demonstrar a importância dos negócios gerados por instituições governamentais. Segundo eles, relacionamentos que ampliem as conexões das firmas com entidades governamentais, sejam de caráter institucional, colaborativo ou transacional, são importantes para a fixação de laços com essas entidades.

Investigações sobre o papel do Conselho de Administração ganham relevância no equacionamento endógeno entre os proprietários e o agente, bem como no âmbito exógeno, no relacionamento com os demais interessados. 0 que os interessados esperam e como o conselho pode contribuir foram indagações propostas por Brennan (2006) ao discorrer sobre as atividades do conselho correlacionadas à performance. $\mathrm{O}$ autor mapeou as atividades exercidas pelo Conselho de Administração e registrou aquelas que se mostraram fundamentais ao desempenho da corporação, classificando-as em três grupos: delineamento da estratégia, monitoramento e controle, representação externa - todas prestam apoio à gestão nos interesses da firma. Com esse extrato, o autor identificou na literatura 19 papéis comumente exercidos pelo conselho que guardam implicações na performance. Especificamente, no grupo de práticas exógenas, destacou as seguintes atividades: promoção do prestígio e da reputação da companhia, participação no relacionamento com organismos externos, assistência à organização na obtenção de recursos escassos, atuação como embaixador e prestação de suporte e aconselhamento ao gestor.

Relacionar a firma ao ambiente externo é importante (PFEFFER, 1972; ZAHRA; PEARCE II, 1989; BOYD, 1990;
PEARCE II; ZAHRA, 1992; DAILY; DALTON, 1994a, 1994b; HILLMAN; CANNELLA JR; PAETZOLD, 2000) e a teoria da dependência de recursos entende que, dentre as atribuições do Conselho de Administração, deve-se incluir o papel de se relacionar com o ambiente externo. Desses estudos empíricos se depreende que, quanto mais representativa a participação de conselheiros outsiders ${ }^{1}$ e a presença do sistema $d u a l^{2}$, com segregação de funções (CEO/Board Chairperson ${ }^{3}$ ), mais intenso é o interlock. Há relação estreita entre a composição do board e o ambiente externo. Conselhos são estruturados com a finalidade de cooptar ou parcialmente absorver importantes instituições externas com as quais as firmas estabelecem relações de interdependência. 0 background do conselheiro, o tamanho do conselho, o número de interlocks e as características dos membros do conselho podem ser importantes indicadores do grau de orientação da organização. A seleção de membros-outsiders com ricos-recursos pode fornecer inestimáveis vínculos com o ambiente.

Essas formulações pressupõem pluralidade na composição dos membros do board, a partir da reunião de conselheiros com experiência em questões relacionadas a controle, gestão, estratégia e política. As organizações podem adotar várias estratégias para reduzir incertezas (BAZERMAN; SCHOORMAN, 1983) e a melhor composição do

1 Outsiders directors são conselheiros externos e insiders directors, internos.

2 Estrutura dual ou duale: quando há segregação de funções; por exemplo, o presidente do Conselho de Administração não exerce funções simultâneas no conselho e na diretoria executiva. 3 Board chairperson é a pessoa eleita para presidir o Conselho de Administração. 
conselho deve estar alinhada com os direcionadores estratégicos da firma. Os atributos do conselho influenciam a performance da firma (ZAHRA; PEARCE II, 1989); daí a relevância do conselho face à incerteza e à dependência ambiental.

Por isso a literatura atribui importante papel político a ser exercido pelo Conselho de Administração na interação com o ambiente externo (GOLDMAN; ROCHOLL; SO, 2009).

\section{CONCLUSÕES}

A literatura que embasa este estudo demonstra nova conotação ao papel do Conselho de Administração. Ligações da firma ao ambiente são mais intensivas e praticadas por empresas que, na dependência por recursos, procuram estreitar vínculos, desenvolvendo laços em prol de seus interesses e protegendo-se de novos entrantes no meio de competição. As características estruturais do ambiente organizacional e o relacionamento social com os atores é que determinam o relacionamento social entre os atores, ou seja, o nível de conflito e interdependência presentes no sistema social (PFEFFER; SALANCIK, 2003). Quanto menor a intensidade de concentração e munificência ambiental, mais acirrados os conflitos sociais e a interdependência, havendo maior interconectividade. Tudo isso converge para a intensidade da incerteza ambiental. Portanto, é coerente deduzir que a incerteza e a instabilidade no ambiente requerem flexibilidade das organizações em suas estratégias de estreitamento com o ambiente.

Nessa relação firma-ambiente, o conselho exerce um papel fundamental. Pode-se inferir da literatura que, embora os membros do conselho tenham a função proeminente de assessorar, aconselhar e monitorar os executivos, têm se incorporado outras atividades com perspectivas importantes. Dentre as quais tem se enfatizado a importância do auxílio à organização na obtenção de recursos escassos, da atuação como representante perante as instituições e o estabelecimento de relações com o ambiente externo.

Nas relações interorganizacionais, a literatura tem apresentado várias formas de se estreitar laços e de reduzir a interdependência com o ambiente. 0 compartilhamento de conselhos entre firmas é um exemplo clássico de aplicação da teoria da dependência de recursos para os conselheiros. Essas ligações estabelecidas com o ambiente são um meio de representação e ação política, bem como facilitar o acesso a recursos de instituições financeiras. Há evidências que esse vínculo é capaz de extrair rendas, mesmo quando os conselheiros não estão diretamente no poder, e até mesmo contribuir na proteção da firma frente a competidores.

As relações sociais externas estabelecidas por conselheiros contribuem positivamente no fluxo de informações do ambiente à firma; daí a contribuição prestada por esses membros às atividades exercidas pelos gestores (executivos), o que proporciona benefícios ao desempenho. Essas relações com o ambiente externo se direcionam para a redução na assimetria informacional e o desenvolvimento de um sentido colaborativo e participativo entre o conselho e os gestores, ao mesmo tempo em que favorecem o processo de tomada de 
decisão. Essas ações reduzem a incerteza perante o ambiente externo, contribuindo para decisões mais acertadas. A priori, todos os benefícios como os promovidos pelo interlocking e das relações que a firma estabelece com o ambiente externo influenciam seus resultados (HILLMAN; ZARDKOOHI; BIERMAN, 1999).

Dessa forma, este estudo buscou contribuir com investigações que se ocupam com as atividades relacionais da firmaambiente. Especialmente como atributo dos membros do Conselho de Administração das firmas. Ao discutir o papel externo do board, com ênfase na perspectiva da dependência de recursos, apresentou várias limitações, pois poderia considerar e enfatizar outros constructos teóricos ao papel do board, como o dos stakeholders e a da rent-seeking, por exemplo. De igual maneira, outros mecanismos de governança mereceriam ser discutidos, como o da estrutura de capital e seu papel influente junto ao ambiente. Assim, outros estudos com esses enfoques podem ser explorados. 0 papel político do Conselho de Administração, por intermédio de estudos empíricos pode ser relacionado ao desempenho das firmas.

\section{REFERÊNCIAS}

AGRAWAL, Anup; KNOEBER, Charles. Firm performance and mechanisms to control agency problems between managers and shareholders. Journal of Financial and Quantitative Analysis, v. 31, p. 377-397, Sept. 1996.

AGRAWAL, Anup; KNOEBER, Charles. Do some outside directors play a political role? Journal of Law \& Economics, v. 44, n. 1, p. 179-198, 2001.

ALCHIAN, Armen; DEMSETZ, Harold. Production, information costs, and economic organization. The American Economic Review, v. 62, p. 777-795, 1972.

ALDRICH, Howard E.; PFEFFER, Jefrey. Environments of organizations. Annual Review of Sociology, v. 2, p. 79-105, 1976.

BAZERMAN, Max H.; SCHOORMAN, F. David. A Limited rationality model of interlocking directorates. Academy of Management Review, v. 8, n. 2, p. 206-271, Apr. 1983.

BERTRAND et al. Politicians, firms and the political business cycle: evidence from France. Unpublished Working Paper, University of Chicago, Nov. 2006.

BOUBAKRI, Narjess et al. Political connections and the cost of equity capital. Paper presented at the European Financial Management Symposium on Corporate Governance and Control, United Kingdom, Nov. 2008.

BOYD, Brian. Corporate linkages and organizational environment: a test of the resource dependence model. Strategic Management Journal, v. 11, n. 6, p. 419- 430, Oct. 1990.

BRENNAN, Niamh. Boards of directors and firm performance: is there an expectations gap? Corporate Governance, v. 14, n. 6, p. 577-593, Nov. 2006.

CADBURY, Sir Adrian. The corporate governance agenda. An International Review, v. 8, n. 1, Jan. 2000.

COASE, Ronald H. The nature of the firm. Economica, v. 4, p. 386-405, Nov. 1937.

DAILY, Catherine; DALTON, Dan R. Bankruptcy and corporate governance: the impact of board composition and structure. Academy of Management Journal, v. 37, n. 6, p. 1603-1617, Dec. 1994a.

DAILY, Catherine; DALTON, Dan R. Corporate governance and the bankrupt firm: an empirical assessment. Strategic Management Journal, v. 15, n. 8, p. 64-654, Oct. 1994b.

DAVIS, Gerald F.; THOMPSON, Tracy A. A social movement perspective on corporate control. Administrative Science Quarterly, v. 39, p. 141-173, 1994. 
DAVIS, James H.; SCHOORMAN, F. David; DONALDSON, Lex. Toward a stewardship theory of management. Academy of Management Review, v. 22, n. 1, p. 20-47, 2 charts, Jan. 1997.

DENIS, Diane K.; McCONNELL, John. International corporate governance. Journal of Financial and Quantitative Analysis, v. 38, n. 1, p. 1-36, Mar. 2003.

DONALDSON, Lex; DAVIS, James H. Stewardship theory or agency theory: CEO governance and shareholder returns. Australian Journal of Management, v. 16, n. 1, June 1991.

DONALDSON, T.; PRESTON, L. E. The stakeholder theory of the corporation: concepts, evidence and implications. Academy of Management Review, v. 20, n. 1, p. 65-91, Jan. 1995.

DOOLEY, Peter C. The interlocking directorate. The American Economic Review, v. 59, p. 314-323, June 1969.

EISENHARDT, Kathleen M. Making fast strategic decisions in high-velocity environments. Academy of Management Journal, v. 32, n. 3, p. 543-576, 1989.

FAMA, E. F. Agency problems and the theory of the firm. Journal of Political Economy, v. 88, p. 288-307, 1980.

FAMA, E.; JENSEN, M. Separation of ownership and control. Journal of Law Economics, v. 26, p. 301-305, 1983.

FAN, Joseph P. H.; WONG, T. J.; ZHANG, Tianyu. Politically connected CEOs, corporate governance, and Post-IPI performance of China's newly partially privatized firms. Journal of Financial Economics, v. 84, p. 330-357, Jan. 2007.

FLAK, Leif Skiftenes; ROSE, Jeremy. Stakeholder governance: adapting Stakeholder theory to e-government. Communications of Association for Information Systems, v. 16, p. 642-664, 2005.

GOLDMAN, E.; ROCHOLL, J.; SO, J. Do politically connected boards affect firm value? The Review of Financial Studies, v. 22, n. 6, p. 2331-2360, 2009.

HART, Oliver. Corporate governance: some theory and implications. The Economic Journal, v. 105, p. 678-689, 1995.

HILLMAN, Amy J. Corporate political strategy formulation: a model of approach, participation, and strategy decisions. Academy of Management Review, v. 24, n. 4, p. 825-842, 1999.

HILLMAN, Amy J.; CANNELLA Jr., Albert; PAETZOLD, Ramona L. The resource dependence role of corporate directors: strategic adaptation of board composition in response to environmental change. Journal of Management Studies, v. 7, n. 2, p. 235-255, Mar. 2000.

HILLMAN, Amy J. Politicians on the board of directors: do connections affect the bottom line? Journal of Management, v. 31, n. 3, p. 464-481, 2005.

JENSEN, Michael C. Agency costs of free cash flow, corporate finance, and takeovers. The Market for Corporate Control, v. 76, n. 2, p. 323-329, 1986

JENSEN, Michael C.; MECKLING, William H. Theory of the firm: managerial behavior, agency costs, and ownership structure. Journal of Financial Economics, v. 3, n. 4, p. 305-360, Oct. 1976.

JENSEN, Michael C.; MECKLING, William H. The nature of man. Journal of Applied Corporate Finance, v. 7, n. 2, p. 4-19, 1994.

JOHNSON, Jonathan; DAILY, Catherine M.; ELLSTRAND, Alan E. Conselho de administração: a review and research agenda. Journal of Management, v. 22, n. 3, p. 409-438, 1996.

JONES, T. M. Instrumental stakeholder theory: a synthesis of ethics e economics. Academy of Management Review, v. 20, n. 2, p. 404-437, 1995.

KLEIN, Benjamin. Contracting costs and residual claims: the separation of ownership and control. Journal of Law \& Economics, v. 26, n. 2, p. 367-374, June 1983.

KOENIG, Thomas; GOGEL, Robert; SONQUIST, John. Models of the significance of interlocking corporate directorates. American Journal of Economics and Sociology, v. 38, n. 2, p. 173-186, Apr. 1979.

LEUZ, Christian; OBERHOLZER-GEE, Felix. Political relationships, global financing, and corporate transparency: evidence from Indonésia. Journal of Financial Economics, v. 81, p. 411-439, Feb. 2006 
LYNALL, Matthew D.; GOLDEN, Brian R.; HILLMAN, Amy J. Board composition from adolescence to maturity: a multitheoretic view. Academy of Management Review, v. 28, n. 3, p. 416-431, 2003.

MINTZBERG, Henry. Who should control the corporate? California Management Review, v. 27, n. 1, p. 90-115, 1984.

MUTH, M.; DONALDSON, L. Stewardship theory and boar structure: a contingency approach. Corporate governance: an international review, v. 6, n. 1, p. 5-28, Jan. 1998

NUNES, Edson de Oliveira et al. Agências reguladoras e reforma do Estado no Brasil: inovação e continuidade no sistema político-institucional. In: NUNES, Edson de Oliveira (Coord.). Rio de Janeiro: Garamond, 2007.

PEARCE II, John A. The relationship of internal versus external orientations to financial measur. Strategic Management Journal, v. 4, n. 4, p. 297-306, Oct./Dec. 1983.

PEARCE II; ZAHRA, Shaker, A. Board composition from a strategic contingency perspective. Journal of Management Studies, v. 29, n. 4, p. 411-438, July 1992.

PFEFFER, J. Size and composition of corporate boards of directors: the organization and its environment. Administrative Science Quarterly, v. 17, p. 218-229, 1972.

PFEFFER, J.; SALANCIK, Gerald R. The external control of organizations: a resource dependence perspective. Stanford, California: Stanford Business Books, 2003.

REDIKER, Kenneth J.; SETH, Anju. Boards of directors and substitution effects of alternative governance mechanisms. Strategic Management Journal, v. 16, p. 85-99, 1995.

SCHOORMAN, F. David; BAZERMAN, Max H.; ATKIN, Robert S. Interlocking directorates: a strategy for reducing environmental uncertainty. Academy of Management Review, v. 6, n. 2, p. 243-251, 1981.

TOWNLEY, Barbara. Foucault power/knowledge and its relevance for human resource management. Academy of Management Review, v. 18, n. 3, p. 518-545, 1993.

WESTPHAL, James D. Collaboration in the boardroom: behavioral and performance consequences of CEOboard social ties. Academy of Management Journal, v. 42, n. 1, Feb. 1999.

ZAHRA, Shaker A.; PEARCE II, John A. Boards of directors and corporate financial performance: a review and integrative model. Journal of Management, v. 15, n. 2, p. 291-334, June 1989. 